\section{Not Just Immobile \\ Moving Drawings and Visual Synecdoches in Neon Genesis Evangelion}

José Andrés Santiago Iglesias

When thinking about anime, stillness is usually pointed out as one of the most defining traits. However, stillness can be used for different reasons (from budget restrictions to aesthetic choices) and in many different ways. Neon Genesis Evangelion ${ }^{1}$ stands out as a paramount example of how anime employs stillness as a powerful aesthetic and visual narrative device.

First broadcast in Japan in I995-96, EVA became an epochmaking series-and later franchise-with a deep impact on anime culture. Over the years, EVA has been praised for its visual innovations. Built upon aesthetic conventions, visual resources and narrative tropes that existed in action-oriented anime series (especially those from the mech $a^{2}$ - or giant-robot-genre), EVA subverted those conventions and rearranged them in a highly novel way. Thus, over the last 25 years, EVA has defined new standards for mecha anime in particular.

Many EVA viewers-both devoted fans and hardcore hatersimmediately acknowledge iconic sequences in which stillness plays a paramount role, whether they opt to praise the director's bold artistic choices or to mock the technical making. The lift sequence, depicting Rei and Asuka, in episode 22; Shinji on the Eva-or, pondering whether or not he should kill Kaworu, in episode 24; and the especially thought-provoking final episodes 25 and 26, are all examples of masterful uses of stillness. Regardless of whether the viewer loves the series or not, these sequences are acknowledged as striking and utterly distinct, often triggering a response of discomfort and alienation,
I Henceforth abbreviated as EVA.

2 Science Fiction narratives featuring battles with 'mechanical' devices, usually involving—although not exclusivelygiant robots.

How to cite this book chapter:

Santiago Iglesias, J. A. 202I. Not Just Immobile: Moving Drawings and Visual Synecdoches in Neon Genesis Evangelion. In: Santiago Iglesias, J. A. and Soler Baena, A. (Eds.). Anime Studies: Media-Specific Approaches to Neon Genesis Evangelion. Pp. I9-48 Stockholm: Stockholm University Press. DOI: https://doi.org/IO.I6993/bbp.b. License: CC-BY 4.0 
encouraging a need for resolve. From a visual standpoint, there is a sense of awkwardness in facing long static shots as characteristic of these iconic sequences, as cinema has accustomed the audience to increasingly accelerated montages, and even anime, though it still displays an abundance of static images, tends to compensate this immobility by means of dialogue and sound. Most visual and filmic characteristics of contemporary anime can be understood through EVA. In this chapter, I will pay attention to three features broadly used across the TV series which are defined by the dynamics between movement and stillness.

The first feature is what I will call, for the sake of argument, 'ratio dynamism.' As highlighted in the opening statement of this chapter, anime is usually defined in terms of immobility. This notion is connected to anime's origins in 'limited animation,' which has grown into an aesthetic device. From a technical perspective, animation criticism has foregrounded the dichotomy between full and limited animation. The first has been largely identified with Disney's long-feature films, their smooth and fluid motion accomplished through a large number of frames per second (fps) and multiple cels, while the latter has been traditionally singled out as one of the most distinctive features of Japanese anime. However, anime is not just about stillness. Instead, I would argue that anime is defined by the combination of sequences with a variable fps ratio, thus creating a certain sense of rhythm. The fact that anime juxtaposes still images that can last up to a minute, with sequences rendered in complex and smooth (i.e., full) animation, distinguishes it from both low-cost cartoons and Disneystyle productions.

In EVA, stillness-in close interrelation with sound-is also used as visual trope in the form of synecdoche. Thus, the second feature I will discuss in this chapter is the use of visual and sound synecdoches as narrative devices, as well as the notion of pars pro toto, as manifested in some intriguing sequences. I am using 'synecdoche' 
(a type of metonym) not in the literal sense, as a literary figure of speech, but rather in regard to its underlying function: referring to one element (the part) to represent an entirety (the larger whole), or vice versa, to borrow from the Latin, pars pro toto and totum pro parte. This idea builds on the argument of non-linguistic metonyms by Roman Jakobson, who is known for the suggestion that "metonymy was the trope that stood at the basis of Realism, of Cubism, and of cinema" (Whitsitt 2013: 28). Moreover, synecdoches often develop as a type of personification by representing human aspects through non-human objects. In EVA, many emotionally intense situations actually take place off-screen, while some specific background objects-presented in still frames-relate what is actually happening in the scene.

The notion of visual synecdoches also allows the connection of the first feature of this chapter with the last one, under the heading of 'moving drawings.' The use of synecdoches and metonymic bodily representations (ultimately, metonymy can be understood as an umbrella term for this sort of indexical link) creates visual connections between anime and other media, for example, the pillow-shot in classic Japanese cinema (Burch I979) and, most significantly, the decompression in comics (Cohn 2007: I 5), closely related to McCloud's concept of panel transitions (1993: 72). Many sequences in EVA can be described in terms of McCloud's 'aspect-to-aspect' transition, as they let the viewer's eye wander around the scene of action.

Thus, by analyzing different sequences, this chapter will address the role stillness plays as a dramatic resource to build up tension. It will also highlight some of the bold aesthetic choices made in the last two episodes of the series, and demonstrate how motion can be achieved through stillness, relying on cels' displacement, rapid horizontal movement and frame speed. Moreover, I will attempt to explain how instrumental immobility is in EVA's use of synecdoches, and how 
these visual tropes end up playing a key role in the way the narrative flows. However, in order to do so, it is important to address Marc Steinberg's concept of anime's "dynamic immobility of the image" (20I2), as it allows the interconnection of anime and manga.

\section{Stillness in EVA}

Since his early works in the I920s, Walt Disney pursued an animation style defined by 'realism,' bespoke technical advancement and refined craftsmanship. During the Golden Age of animation (I934-4I), Disney pushed his cartoonists and engineers to reach even higher levels of sophistication, ultimately achieving what is usually regarded as the apex of cel animation, and setting the standards for any future feature-length productions. Disney cartoonists' pursuit of 'realism' is not the opposite to stylized character designs or non-accurate bodily proportions-which are quite usual in many of Disney's cel-animated feature-films-but rather movement: movement understood as the fluidity, smoothness and lifelikeness of motion, allowing drawn characters to drift naturally on screen and acquire a certain sense of weight and physicality. In order to accomplish this, animators used a large number of frames ( 18 to $30 \mathrm{fps}$ ), as well as techniques like rotoscoping, to accurately capture bodily movements. Smooth motion thanks to a high frame rate is the defining trait of 'full animation.' It goes without saying that full animation is not a style exclusive to Disney. Many studios and directors have embraced it. Studio Ghibli's films—and most notably Hayao Miyazaki's internationally acclaimed works-as well as Toei Animation productions, among many others, are examples of the fact that Japanese motion pictures are by no means strangers to full animation.

In its early stages, anime relied almost entirely on limited animation techniques such as the extensive use of still images and a low frame rate ( 8 to I $2 \mathrm{fps}$ ), sometimes drawing just the keyframes while omitting the inbetweens (i.e., the intermediate positions). Thus, the 
combination of still images, in addition to the dynamics between motion and interrupted movement, is what has come to define anime. Characters' jerky movements have often been deprecated as poor and badly rendered, hindering physical mobility. However, according to Steinberg, it is precisely this motion that allows anime series to entice both affective investment and circuits of return (20I2: 5).

The distinction between full and limited animation is a recurring topic in academic discussion. It helps to identify many of anime's defining traits. However, setting this distinction in dichotomous terms risks to polarize movement versus immobility. As a result of such polarization-and of McLaren and Disney's dominating assumptions regarding what 'good' animation should be-limited animation has been historically regarded as a lesser version of full animation or, at least, a version that does not meet the artistic expectations of the latter. Notwithstanding, Lamarre, Steinberg and Gan, among others, have promoted a simple, yet important notion: Anime's techniques of limited animation are different, not lesser.

EVA is full of examples of limited animation, from both formal and narrative standpoints. In episode 2 , the clever visual juxtaposition between the two POV (point of view) shots of the ceiling-one of the hospital room where Shinji is confined after his first fight with an Angel, and one of his room at home when he recalls the battle of the previous day-consists of a series of still images, followed by a high-speed sequence of different still images played at a rate of one image per frame, to represent how Shinji's faded memories of the fight are quickly coming back (00:17:26). The conversation between Major Katsuragi and NERV Commander Gendō Ikari in episode 6 lasts 2I seconds (00:06:IO-00:06:3 I), but it is entirely comprised of two static shots, and 'animated' by a variation on shot-reverse-shot and cross-dialogue techniques (Professor Fuyutsuki speaking while the screen shows a still image of Major Katsuragi). Shot-reverse-shot, subjective shots and cross-dialogues are well-known cinematic tools, which allow the presentation of a speaker's voice (off-screen) with 
the listener's emotional reaction (on-screen). Thus, characters are animated, despite the fact that the entire sequence is built on still images alone.

The above example helps in understanding Steinberg's dynamic immobility of the image. According to Steinberg, anime is no longer concerned with pursuing a smooth, naturalistic movement; instead, it has grown apart from the dominant cinematic style in animation into a form of its own, ruled by a unique set of rhythms of motion and stillness. In this sense, anime's traditional 'lack of motion' is not to be regarded as a limitation, but as a means to depart from filmic conventions. Steinberg connects anime's specificity to other mediakamishibai and, most importantly, manga-which had provided early viewers with the necessary tools to understand that movement can be found in stillness. For Steinberg, this transmedia interrelation of still-but-dynamic images explains anime's potential for setting up connections across media forms as well as media networks (20I2: 6-7). Furthermore, he understands the unique dynamism found in manga and kamishibai as follows:

On one hand, this dynamically still image functioned as a kind of aesthetic precursor to anime, allowing spectators to feel the anime image moving and be moved by the image effectively-even if the image was formally immobile. On the other hand ... manga's development of the techniques for the creation of this dynamically still image provided the toolbox for the development of devices and techniques essential to the production of anime's limited animation. (Steinberg 2012: 33)

Anime uses many techniques to produce movement from still images, like sectioning (animating only a part of the character, such as the mouth or eyes) and high-speed mosaics-in EVA, still frames from previous episodes are widely used, playing at I 2 fps, very much like the opening of the series itself-but also background displacement and other cinematic effects, such as panning, tilting, traveling, zooming, and focus and out-of-focus sequences. The result is dynamic, 
despite the fact that many episodes present many sequences comprised of long shots of still images. Steinberg highlights the idea that anime presents "unique rhythms of movement and immobility" (2OI2: 5). However, this notion is mostly focused on the still images themselves, and how they can be utterly dynamic despite their immobility (i.e., not being smoothly animated). In this regard, I would like to expand on the idea of "unique rhythms of movement and immobility," focusing on the alternating ratio of frames per second in contemporary anime.

\section{Ratio Dynamism}

In live-action cinema, a long static shot is often deemed as a classic yet risky move, not too closely connected to current filmic language and at times seen as too harsh, in visual terms, for the audience. It is well apparent that in a long static shot, if no striking action is taking place, a few seconds can trigger a sense of estrangement in the viewer, as if time were stretching out and lasting longer than it should. Therefore, a static shot of 5 or even ro seconds has become quite unusual in today's mainstream cinema. But in any given static shot-be it of a landscape or an empty room-there is always a certain degree of movement, since the image is footage of a real scene: a blade of grass that moves, a change of light in the room, or small objects that drift in the background.

However, this is not the case in EVA or any other mainstream anime. Nowadays, anime's 'limited animation' no longer refers to a low number of frames per second, but rather to a variable ratio. Thus, it is not so much that anime is poor in movement, with an average of four or eight frames per second, but rather that it features a still image, sustained for several seconds, and then links it to an elaborate action scene, in which the animation is rendered with I 8 or even 24 fps. Stillness is, indeed, one of anime's most defining traits, and these still images can appear very dynamic, but current 
4. Sectioning usually refers to the fact that animators change just one element (like the eyes or the mouth of the character) rather than animating all the nuances of facial expression and other complex movements. anime is characterized by combining many different rates with filmic intention, leading to extremely sophisticated and complex animated sequences. This on-demand ratio of frames per second-which I call ratio dynamism - gives a new meaning to Steinberg's notion of movement and immobility, expanding the idea that anime has a unique rhythm. Animation researcher Antonio Horno highlights the involved aesthetic emphasis, as distinct from a more technical approach: "The evolution in anime in the past few years ... harmonizes the movement of the drawings and balances the number of photograms, thus generating a new aesthetic ..." (2014:87). Ultimately, the frame-per-second ratio is nothing but a tool in the hands of the animator (one tool in a vast collection of animation techniques) related to the intended speed, smoothness and fluidity of the motion.

Consequently, anime shall be understood as "a style of animation based on the interruption of motion and the extensive use of still images" (Steinberg 20I2: 3). The use of still images enables an impression of movement through a resourceful employment of filmic montage (shot-reverse-shot), dialogues, sound and other auditory elements, and a simplified parallax effect. Furthermore, ratio dynamism could be considered one of the most distinctive traits of contemporary anime. In EVA, the wide use of long static shots of one and the same still image answers (beyond production issues) to an aesthetic and narrative need.

Gan (2008) has proposed to speak of 'selective animation.' Her notion is concerned with the animator's choice and highlights the intentionality in choosing still images, 'jerky' movements and limited animation. Thus, 'selective' denotes not only the fact that the filmmaker decides on what to move, with techniques such as sectioning ${ }^{4}$ or a variable image-per-second ratio, but also when to move, stressing the artistic choice, and foregrounding anime's unique rhythm between motion and stillness. However, Gan focuses on the voluntary introduction of stillness, rather than the way in which rhythm and pace 
change, that is, technically and conceptually speaking, by means of ratio dynamism.

As jerky movements, stillness and ratio dynamism become some of anime's defining traits, their widespread use applies not only to TV series, but also to film productions (especially those based on franchises). In these latter productions, technical-stylistic features from the original show coexist with some high-budget features, such as the massive use of CGI to animate complex action sequences and elaborate backgrounds and settings. The 2007 theatrical reboot Evangelion: I.O You Are (Not) Alone mimics one of the original opening scenes from the initial EVA series-namely, when Shinji first arrives to Tokyo-3 and expects to meet Misato-matching perfectly almost every shot, but also the variable fps. The backgrounds are extremely detailed, revealing not only the higher budget invested in the movie (as expected in theatrical productions), but also the I2-year time gap between the two productions. However, the distinctive pace of the sequences remains the same, since the variable amount of fps in those scenes is the same.

From a purely technical perspective, the widespread use of ratio dynamism and the generalization of disruptive technologies such as CGI suggest that contemporary anime can be placed-in terms of smoothness and frame rate-halfway between limited and full animation. This hybridity has become common not only in theatrical anime films, $\mathrm{OVA}^{5}$ and high-budget series for streaming platforms, but also mainstream TV anime series. Steinberg wrote: "Heterogeneity of image styles became the norm within television anime, rather than the exception. For this formal reason it is also not surprising to find that anime producers use $3-\mathrm{D}$ animation in a patchwork style" (20I2: 5). CGI allows the use of cinematic camera movements difficult to recreate with usual drawing techniques and rendered entirely 'on ones, ${ }^{6}$ but keeping the traditional cel-look style. Moreover, in contemporary TV anime series, it is not uncommon for
5. OVA, abbreviation of Original Video Animation; films and series to be released directly to home video.

6. A way to understand the fps ratio is to talk about animation 'on ones,' 'twos' or 'threes.' This denomination refers to the number of times a given image is repeated as a frame while creating the illusion of movement. The smoothest motion comes from animation made on ones, meaning that every single frame depicts a different image. Thus, in production with a speed of $24 \mathrm{fps}$, each second will be composed of 24 different images. 'On twos' means that every image is repeated twice, hence I 2 different images per second. Finally, when images are repeated three times-or using a different image for every three frames-it is described as 'threes,' with a ratio of eight images per second. Of course, this ratio can climb as much as the animator wants, eventually arriving at completely still images. 
two different speeds to coexist (a variable fps rate of sorts), relying on still images for narrative reasons and eye-catching sequences with a high fps ratio for spectacle, which results in a rich and extremely fluid animation.

In contemporary productions, animators are capable of rendering visually astonishing sequences with an incredible sense of speed and movement by means of 'trade-off.' This technique, as its name suggests, applies to a balance achieved between two desirable but incompatible aspects. In anime, this means a compromise whereby the drawn details (shading, clothing and accessories, and even characters' facial features) are sacrificed in exchange for a dramatic increase in the number of frames, resulting in an extremely smooth motion. Usually handled by the leading animators, these short pieces excel in sakuga-especially well-drawn and technically elaborate imageswhile the secondary team focuses on more mundane and generally less showy parts.

A variable fps rate means that, instead of animating all sequences in the same way with a fixed number of frames (in anime, usually 'on twos' and 'threes'), the amount of images per second is tailored to the narrative nature of the sequence and its specific aesthetic demands. Dialogues, landscapes, moments of reflection and observation by the characters or pillow-shots rely deeply on still images or partial movements (by means of sectioning). On the other hand, quick action sequences and naturalistic depictions of bodily movement usually involve a higher frame rate ( 18 to $24 \mathrm{pfs}$ ).

Anime's so-called limited animation is defined by the extensive use of immobility and decompression, but as a medium anime is also defined by a wide range of topics and complex story lines, the interplay between volume and flatness, complex-built and sophisticatedly rendered world-settings, engaging character designs and a unique drawing style. This style serves as a distinctive trademark, a part of anime's own identity, with a clear aesthetic and narrative purpose. 
What was originally born from necessity (as a means of saving time and budget) has evolved into an aesthetically complex way of animating stories. Furthermore, ratio dynamism and stillness-or the tensions between motion and stillness-have become two of anime's major traits, creating movement though different resources, but also allowing for a deep emotional connection with the viewer. For Steinberg, as well as for Lamarre, anime's animation is not defined by immobility, but rather by a different kind of dynamism of the still image. EVA perfectly illustrates these tensions, as phenomenal animation sequences coexist with other rather poorly rendered ones. Yet, most importantly, EVA shows the aesthetic and narrative potential of the filmic resources in limited animation as only few anime series can, raising the use of stillness and a variable fps ratio to new stylistic heights.

\section{Pars pro toto}

At the beginning of this chapter, I presented synecdoche as a type of visual metonym used to refer to a part to represent the larger whole. Yet, I use the notion of synecdoche as a trope in a looser way than cognitive science and semiotics, namely, as a means to convey the idea that many sequences in EVA, comprised of still images, make sense despite their seeming limitations. Actually, synecdoches have been largely used in cinema as a narrative device. Chandler states how in filmic media a close-up can be simply considered as a synecdoche:

Indeed, the formal frame of any visual image (painting, drawing, photograph, film or television frame) functions as a synecdoche in that it suggests that what is being offered is a 'slice-of-life', and that the world outside the frame is carrying on as in the same manner as the world depicted within it. This is perhaps particularly so when the frame cuts across some of the objects depicted within it rather than enclosing them as wholly discrete entities. (2002: I33) 
Jakobson and Halle explained how metonymy and synecdoche are both based on contiguity (1956:95). Synecdoche, as a trope, relies heavily on the audience's logical associations 'filling the gaps' (What is happening off-screen? What are these objects telling me about the ongoing action? What does that sound represent?). In EVA, those gaps are easily filled, allowing for a consistent flow of events. However, on closer inspection, the viewer will realize that many clips-lasting several minutes in each episode-are actually arranged as a series of still images, sometimes not even depicting the foreground action, but inferring what is actually happening by means of context and logical association. Sound effects, off-screen dialogues and crossed dialogues help to produce a passing-of-time effect in the face of still images. While the use of sound effects is broadly applicable to the entire audio-visual medium, the other two traits are cleverly used in anime, and quite specifically in EVA. For example, at the beginning of episode 24 (00.02.05), Asuka and Shinji have a bitter and quite heated off-screen argument about Kaji's disappearance and likely death. While both characters are screaming at each other, the clip-consisting of four different shots, the first three rendered as still frames and the last one partially animated-provides ambient information apart from the actual action, but sufficiently informative to infer the ongoing situation. The first shot is a wide-angle, still image of the dining room with the coffeemaker on the table; it is followed by a close-up of the very same coffeemaker, another still image of two empty cups on the table and a final shot of the coffee spilled all over the floor. The whole clip is resolved with a fifth shot of Asuka's face, barely animated by means of sectioning (Fig.I.I).

Interestingly, through an ellipsis, the next sequence returns to Asuka a few days later, naked and in a woeful physical and mental condition, having lost her ability to be an Eva pilot and hence her life meaning. Once again, the sequence combines several still images with a close-up of Asuka. As she speaks, her lips move to match with 

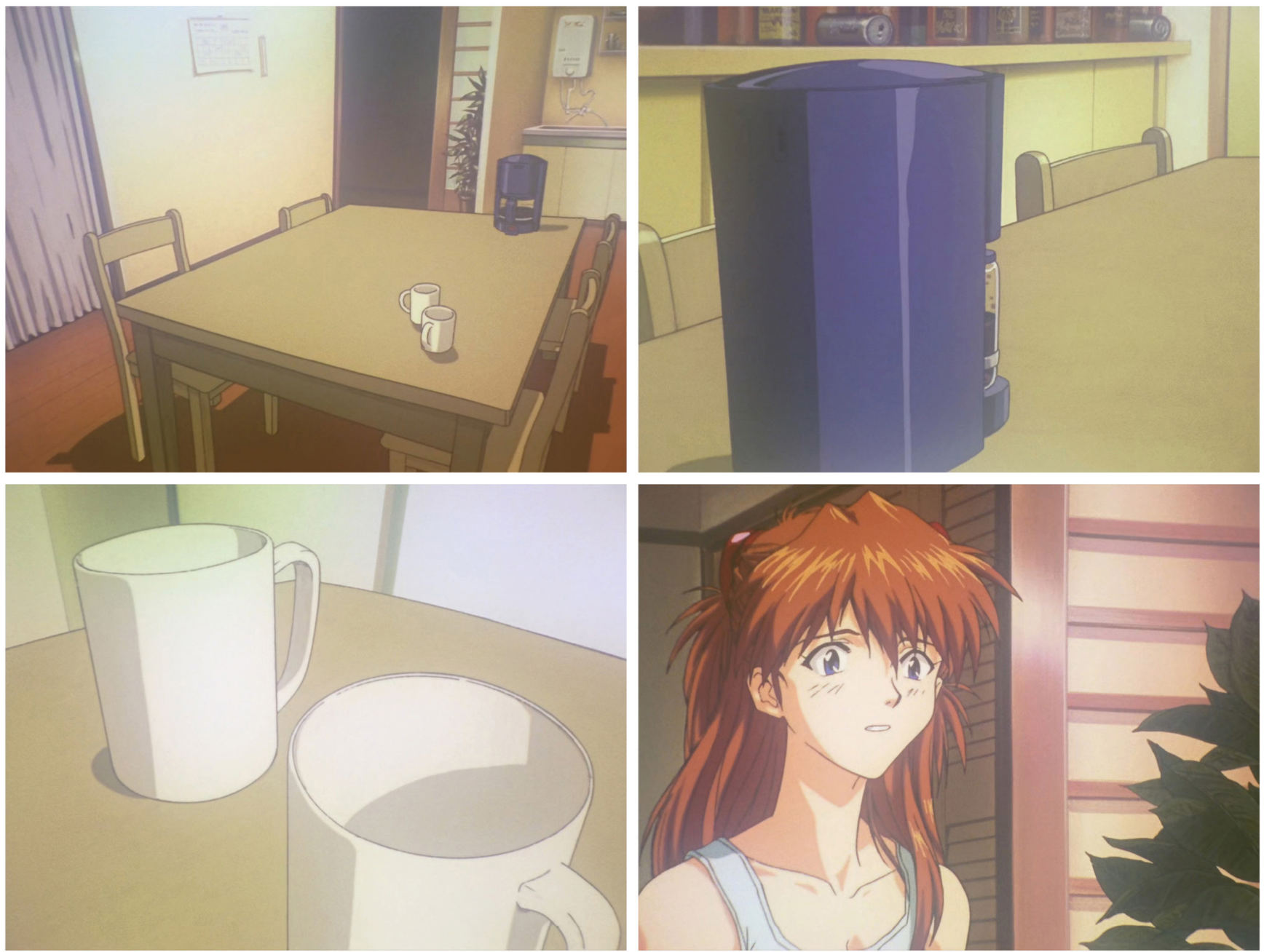

her voice, but in a limited fashion, by means of repetition and sectioning. Instead of producing a realistic depiction of her mouth (via lip sync), the sequence is confined to three different instances in variation-lips fully opened, fully closed and an intermediate stageallowing for minimum lip movement with a convincing impression of vocalization (Fig.I.2).

Figure 1.1. Off-screen argument between Asuka and Shinji at the beginning of episode 24 , consisting of four different shots. (c) khara, inc. 

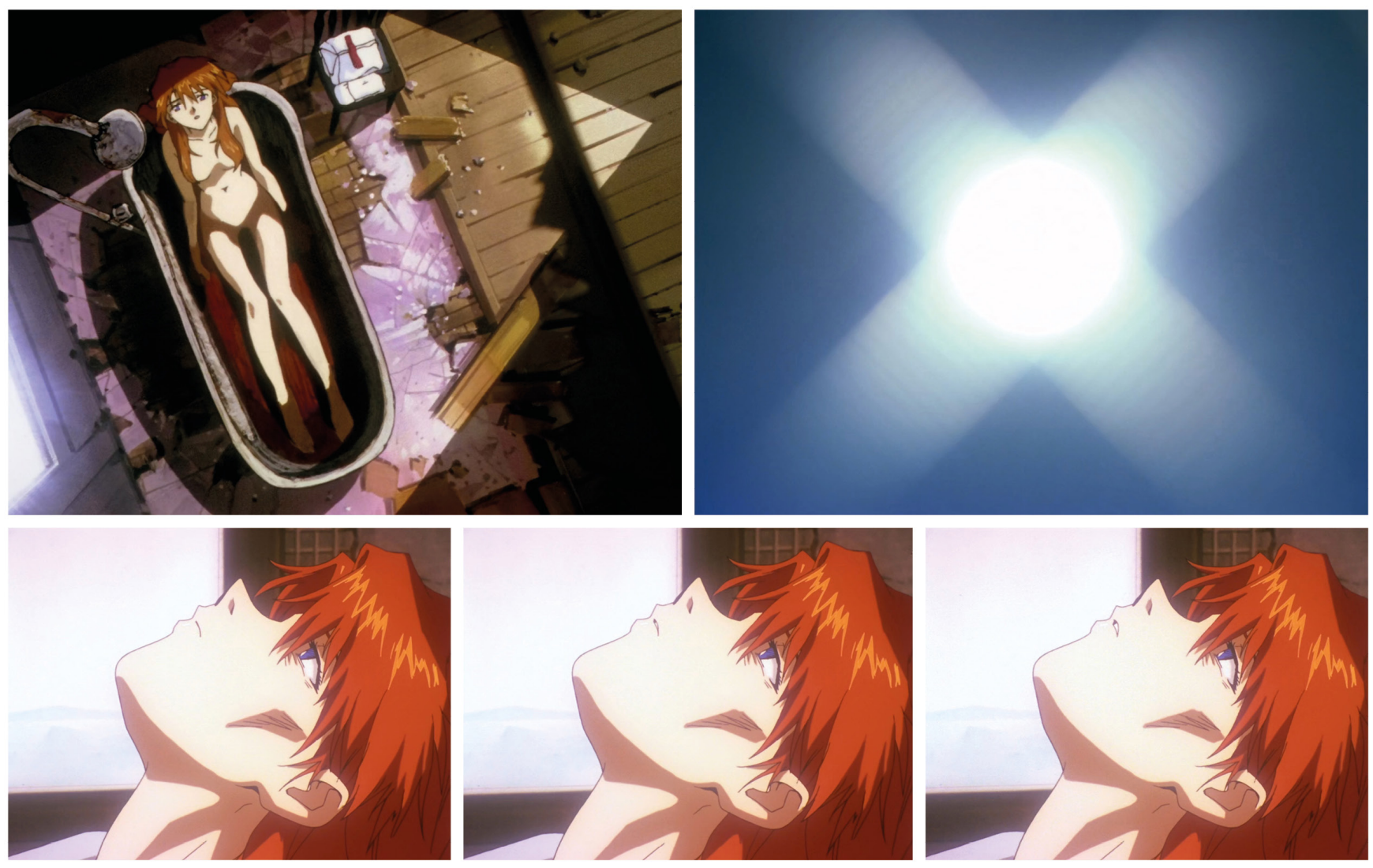

Figure 1.2. Asuka in episode 24, having lost her ability to pilot the Eva 02. As she speaks, the sequence is barely animated by means of sectioning. (C) khara, inc.
These are just a couple of humble examples of how synecdoche operates in EVA, often combined with ellipsis and other narrative tropes. Nevertheless, throughout the whole series, an array of synecdoches frequently appears, many of which allow the tracing of a visual connection from anime to other media.

EVA's episode 24 includes a scene celebrated as one of the most striking, iconic and powerful uses of a still image in anime, portraying Shinji and Kaworu's epic battle, which ends with the death of the latter. As Kaworu reveals himself to be Tabris-the I 7 th and final Angel-Shinji chases him on the Eva-or to the Bottom of the Dogma Terminal. At some point, Shinji grabs Kaworu's fragile body-whose 
appearance is that of a teenager-with the massive fist of the Eva-oI, and begins pondering whether he should accomplish his mission and eliminate the threat posed by Kaworu, or refuse to destroy his only friend. Lasting one minute and five seconds (00:2 I:5 5-00:23:00), the still image of the Eva-or holding Kaworu in its hand (Fig.I.3) presents a really bold aesthetic choice. The only sign of the passing time is the soundtrack (analyzed in depth in Heike Hoffer's Chapter 3 ). In this scene, the still image has a narrative and aesthetic function, but it mostly helps to build momentum and suspense in an attempt to convey Shinji's psyche, the stalemate in which he has to choose between destroying what may be his only friend and saving humanity. Metonymically speaking, it could be argued that in this sequence, the Eva-or is no longer a machine, but a visual representation of Shinji himself.

Interestingly, this scene is rendered in a simple way, with a quick fadeout to a black screen and a squishing sound, and then Kaworu's severed head falling into the fluid that floods the room. This visual expression responds to a narrative and aesthetic intention, but also to production issues, as it avoids having to draw in detail the beheading. In this regard, the long sequence can be understood as time in pause rather than a frozen image. In the same way that Groensteen (2007) affirms the 'iconic solidarity' between panels in comics (in which one panel modifies the next, and in turn is modified by the preceding one), the one-minute-long still image in episode 24 appears as passing time, because there is a sequence that precedes it and a resolution: the death of Kaworu.

In episode 22, there is another example, the lift scene (Fig.I.4) depicting Rei and Asuka, with no exchange of words. It has often been highlighted as one of EVA's most prominent usages of stillness, but it has also been heavily parodied by fans as an unnaturally lengthy shot. Lasting 53 seconds (OO:IO:I I-OO:I I:O4), most of the time there is a still image with no movement at all, and the passing time is primarily defined by the ambient sound. The only movement that can be felt for almost a whole minute is an occasional blink of Asuka (which 


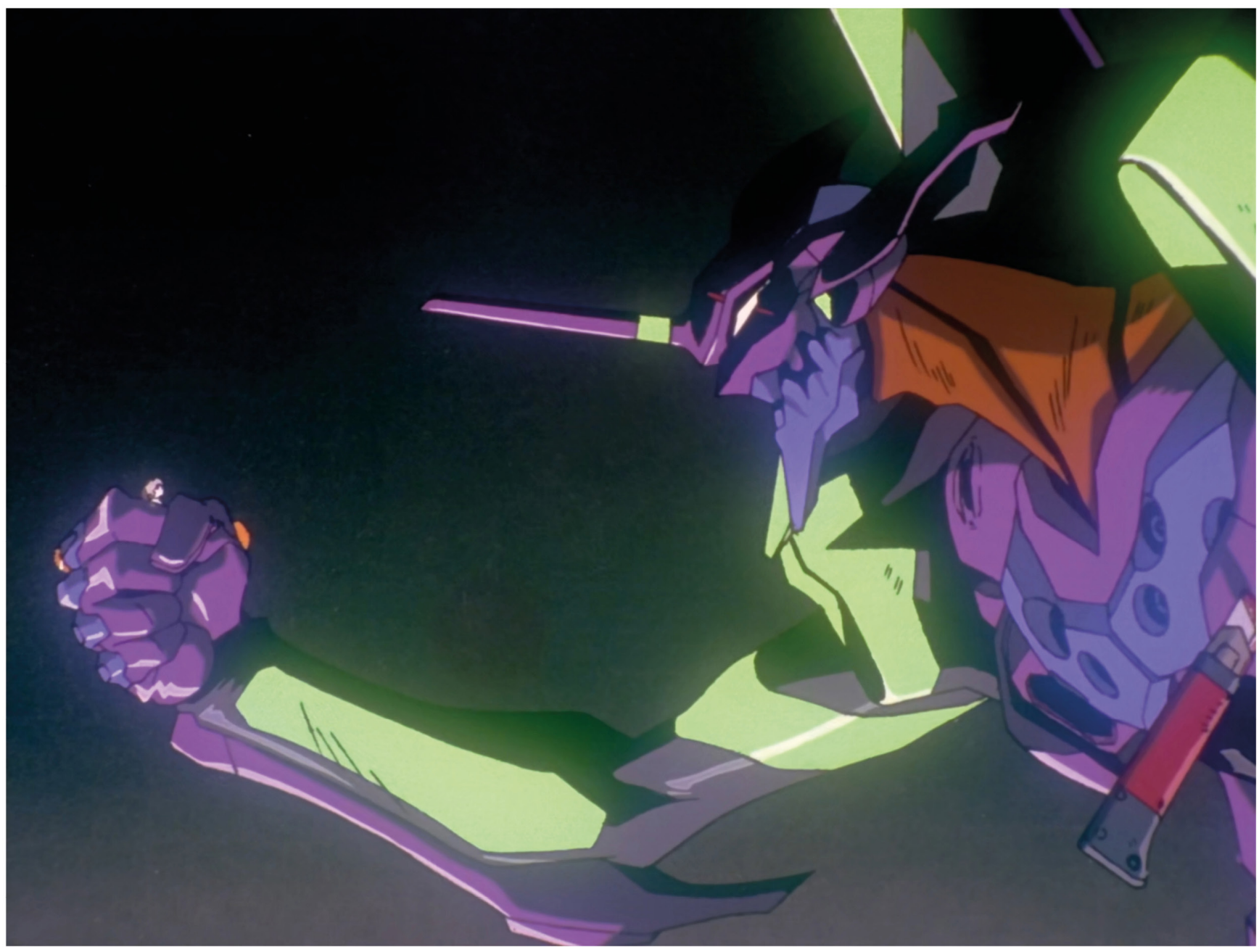

Figure 1.3. In episode 24, the still image depicting the Eva-or holding Kaworu lasts one minute and five seconds (I'O5”). (C) khara, inc. does not even involve a complete change of frame as the only animated object is Asuka's eye as it closes and opens again, by means of sectioning), as well as a twitch toward the end of the scene involving a simple modulation of four frames. Ultimately, director Anno's bet on immobility proves successful, as the sequence recreates the social awkwardness of being stuck in a lift with someone you simply don't want to share the room with. 


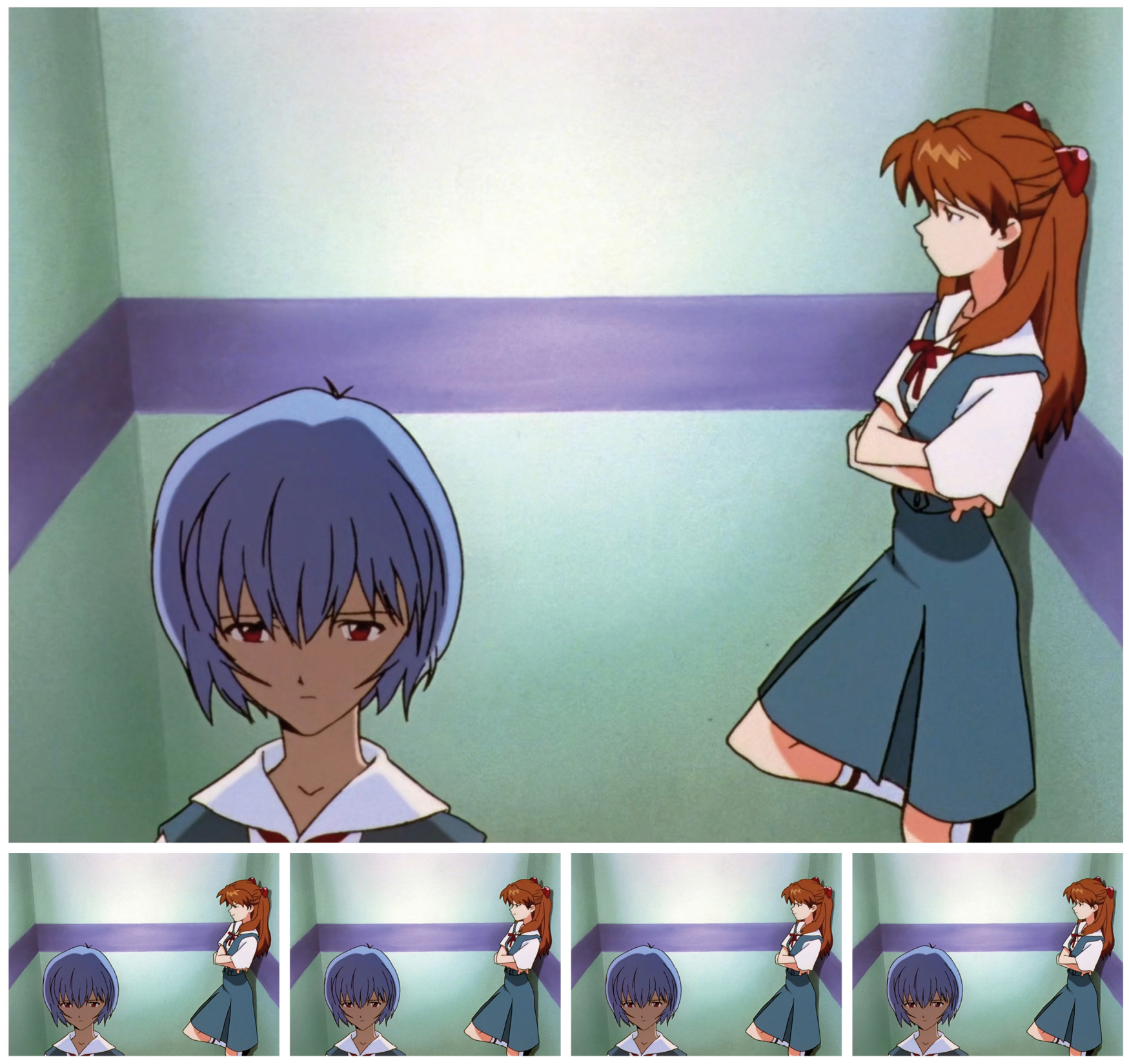

Figure 1.4. The lift scene in episode 22. () khara, inc. 
However, as in the previous example, tension created by the almost frozen image in that scene is achieved by means of synecdoche. After arguing, Asuka slaps Rei and leaves in a rush. In actuality, the viewer never gets to see how Asuka slaps Rei, but rather has to infer it from the black fade-off of the image and the sound, which is technically almost identical with the previous example from episode 24. In the next shot, as the tension is already solved, Asuka screams at a standing Rei and leaves in a rush. The invisibility of her action, the black fade and the use of a sound synecdoche again help to avoid drawing a complex scene with elaborate movements involving both characters.

\section{Moving Drawings}

Connections between manga and anime are well known to academics and enthusiasts alike. A large number of anime titles originate as adaptations of manga series. Nonetheless, it isn't unusual that a successful anime series leads to the publication of a derived manga work. ${ }^{7}$ Such is the case of EVA. The original animated series paved the way for several manga spin-offs, as well as fan-created stories in peer-produced publications (dōjinshi). The connections between manga and anime pertaining to production, distribution and marketing aspects are obvious. On a formal and aesthetic level, there are many similarities that bind both media. The concept of database coined by Hiroki Azuma (200I), widely applied to anime for the construction of characters, can also easily be applied to the fictional imaginary of

7. Addressed in depth in Olga Kopylova's Chapter 8.

8. A style of caricature where characters are drawn in a comical and exaggerated way, usually depicted with small bodies, short and chubby limbs and oversized heads. manga. Likewise, manga isotypes and morphemes (Cohn 20I3), along with the super-deformed and $c h i b i^{8}$ versions of characters, have been adopted by anime. However, beyond these obvious similarities regarding conventionalized visual elements, there are abstract connections between manga and anime concerning issues such as rhythm, page layout and montage, some of which become quite clear in EVA. 
Shinji's shaking hand while he is talking with his father Gendō is a simple yet clever example of synecdoche different from the previous examples. The trembling hand shows his anxiety, but his face remains off-screen while he speaks, because the sequence is more invested in depicting Shinji's awkward relation with his fatherand thus his problems with communicating-rather than what he is actually saying. In a similar way, Shinji or Asuka appear in extreme close-up - an odd and rather dramatic framing in cinematic termswhich draws attention to their mouths and leaves their eyes out of the frame. Ultimately, this has a double dramatic effect: on the one hand, highlighting the effort it takes for them to verbalize intimate and personal information; on the other, actively omitting their eyes serves an emotional intent. This form of close-up-choosing to highlight a secondary element, like a body part, rather than the face as a whole-is by no means unique to anime or EVA, but is used broadly in cinema. Indeed, as highlighted in the previous section, in filmic media a close-up is but a type of visual synecdoche. However, the abundance of these shots in anime in general and EVA in particular is truly noteworthy.

Shots of partially framed faces, feet, hands, legs or any other images of objects and places easily allow the identification of the character to which they refer. Misato and Kaji's sexual encounter in episode 20 (00:19:49) is yet another example of this type of synecdoche (Fig.I.5). The whole sequence consists of a simple array of shots, most of them still images of close-ups and off-action objects. It starts with Misato and Kaji's interlaced hands, followed then by a detail of one of the lights on the ceiling, a framed shot of Misato's legs, an extreme close-up of Kaji's face followed by another extreme close-up of Misato, and a still image-lasting 30 seconds-of the cabinet in the room, on top of which there are a glass of beer, a condom wrapper, a lighter and an ashtray, all shown while the two characters talk to each other. The whole sequence 

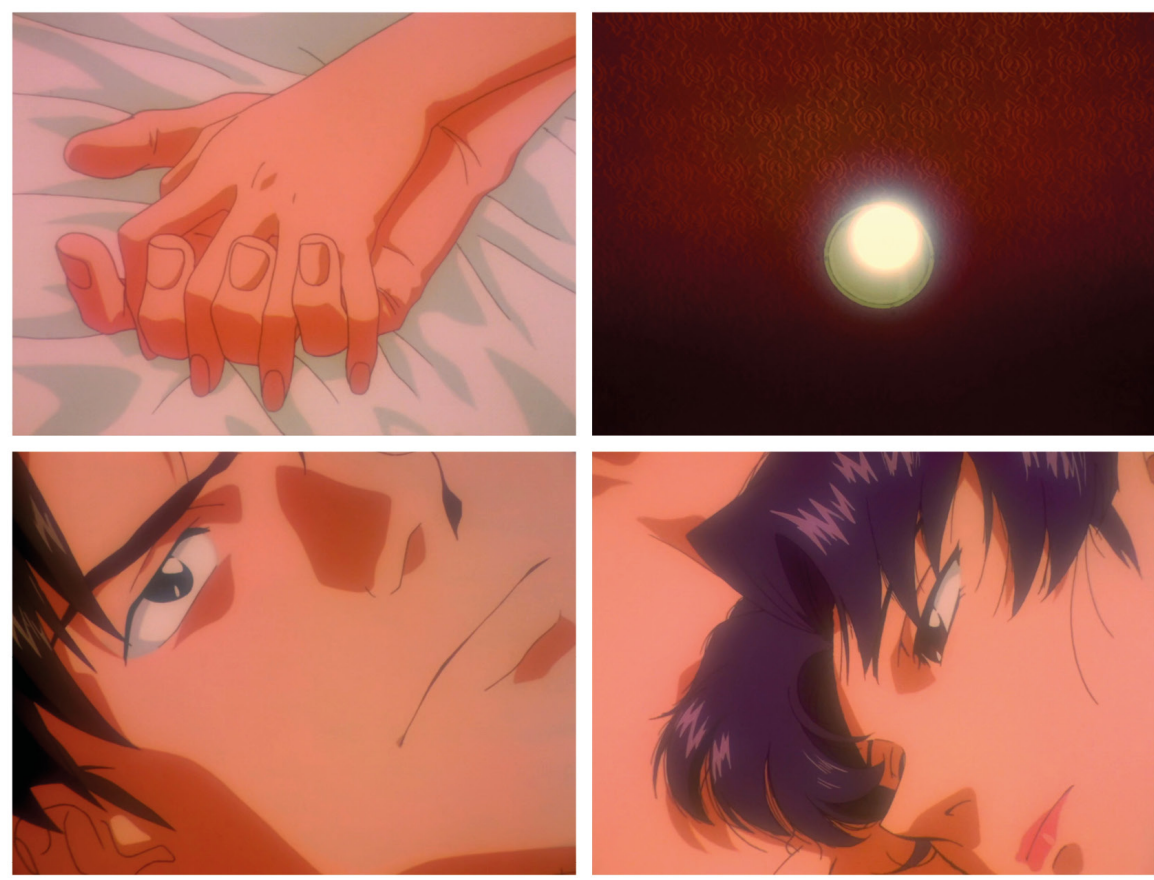

Figure 1.5. Six frames from Misato and Kaji's sexual encounter in episode 20. (C) khara, inc.

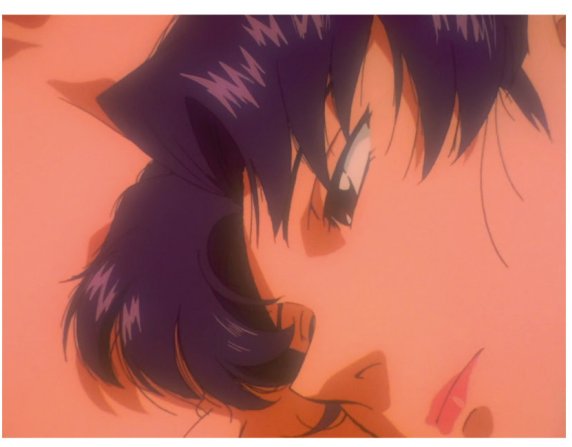

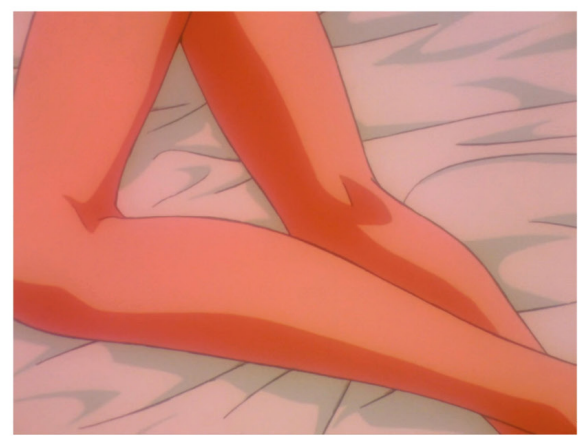

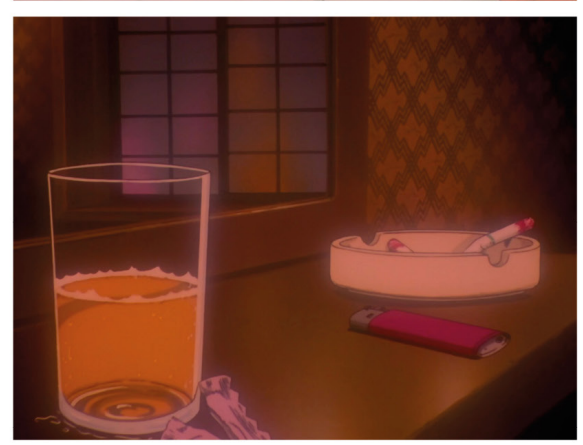

is rendered almost entirely in still images of secondary information combined with the ongoing off-camera dialogue, rather than the actual depiction of the characters. This peculiar interrelation of shots is actually reminiscent of panel transitions in manga, such as McCloud's 'aspect-to-aspect,' and the pillow-shots in Japanese classic cinema. First coined by Burch (I979), who borrowed the term from Japanese poetry, 'pillow-shots' refer to scenes composed of apparently random shots, depicting aspects secondary to the main action taking place. According to Burch, these shots "suspend the diegetic flow [...] while they never contribute to the progress of the narrative proper, they often refer to a character or a set, presenting or re-presenting it out of a narrative context. Pillow shots (the term is derived from Japanese poetry) most often achieve their uniquely de-centering effect by lingering unexpectedly on an inanimate object" (I979: I60). 
This notion is close to McCloud's 'aspect-to-aspect' panel transition. According to McCloud, aspect-to-aspect transitions set a "wandering eye on different aspects of a place, idea or mood” (I993: 74) and are far more common in manga than in European or American comics. McCloud explains that such panel transitions are used to define the overall mood or a place in a given scene. The creation of the mood in the above-mentioned EVA sequence (the two lovers getting intimate) and the room is built on the described set of still images, which can be almost literally explained with McCloud's words: "... rather than acting as a bridge between separate moments, the reader [in EVA, the viewer] here must assemble a single moment using scattered fragments" (I993: 79). Ultimately, McCloud comes to the conclusion that this particularity of manga can be explained as an art of the interval, and that what is omitted is actually as important as what is depicted. This is exactly what happens with visual synecdoches in EVA.

The final two episodes ( 25 and 26) created great controversy upon their release and continue to raise heated debates among anime enthusiasts worldwide. Both episodes deviate from the previous storyline and present a puzzling introspection into the main characters. Moreover, they are almost entirely comprised of still images, connected by monologues and dialogues both in voice and script (white text on black ground), sound effects and the soundtrack.

Pioneering filmmaker and animator Norman McLaren wrote: "Animation is not the art of drawings that move but the art of movements that are drawn; what happens between each frame is much more important than what exists on each frame; animation is therefore the art of manipulating the invisible interstices that lie between frames." This famous quotation is referenced by Lamarre in the early pages of The Anime Machine (2009), when he presents the key ideas to be developed in his seminal book. Lamarre argues that when it comes to anime, compositing-creating an image through layers
9. This quote has been consistently included in books on animation, often referencing a third-party source. La capture de mouvement: Ou le modelage de l'invisible (2014) by Marco Grosoli and Jean-Baptiste Massuet (Eds.) provides a very early reference to the quotation ( $\mathrm{p}$. I7I), apparently written by McClaren himself at his work-desk, and spread by André Martin in the journal Cinéma 57, published by the Fédération Française des Ciné-clubs in I957. 
and invisible spaces between them-is more important than character animation. McLaren claimed that "how it moves is more important than what moves. Though what moves is important, in relative order of importance, it's how it moves that's the important thing" (McWilliams I99I: I05). However, McLaren's statement clashes with anime's current dynamics. In anime, drawings are moved, rather than movement being drawn. Or, as Lamarre points out, "this is precisely what happens in limited animation: you move layers rather than animate characters" (2009: 66). EVA's episodes 25 and 26 are a testament to this.

At some level, episodes 25 and 26 show a joy of experimenting with animation. Many of these resources are used by director Hideaki Anno in order to meet schedule and economic constraints. However, it is equally true that he employed many techniques typically used in combination with still frames. Apart from the regular still images, episodes 25 and 26 include text slides and the widespread use of bank-images, ${ }^{10}$ sequences and shots from previous episodes dubbed with a new dialogue, or sometimes manipulated with filters to produce a surreal effect. In these two episodes, Anno also uses production sketches and rough intermediate materials, collages (like Misato's torn portrait fixed with actual sellotape, or text images composed with newspapers fonts), seemingly random photographs (in a similar way to McCloud's 'non-sequitur' transitions, all of which provide texture to the sequence, but are hardly related to the ongoing action depicted in the sequence) and even abstract Rorschach test-like mirror paintings.

There are three sequences in episode 26 which, from a visual standpoint, approximate abstract animation. Notwithstanding, these sequences deserve deliberate analysis as they push the graphical quality of the image further, accentuating the articulation between

Io. Addressed in depth in Ida Kirkegaard's Chapter 2. movement and stillness. The first sequence is a colorful display of over 300 still images-mostly recycled from previous episodes, 
but also including photographs, random textures (like scanned bubble rapping) and intermediate materials (sketches, storyboards, script pages and so on)-superimposed like a $3 \mathrm{D}$ mapping projection onto Shinji's outlined face (Fig.r.6). At a rate of one image per frame, Shinji's masking-layer effect shows his traced silhouette on a neutral and undefined plain-colored background, while his face overlaps with background images in a pattern that appears abstract due to the speed at which the visuals are projected. This sequencelasting over 40 seconds (00:06:48-00:07:30)—is a great example of how speed and change of images (despite their underlying flatness and stillness) create a sense of motion which does not necessarily involve drawing movement or dynamic immobility. As Steinberg states, anime is "a style that was free to emphasize graphism over volume, graphically immobile dynamism over smoothness of movement" (2OI 2: 35 ).

Moreover, the whole sequence extends the conceptual notion of synecdoche. Ultimately, the flow of images-depicting Shinji's emotional journey through the events that have taken place throughout the whole series-materializes the very idea of pars pro toto (a part for the whole) when he is trying to answer his own question ("What am I?" [sic]), depicting different facets of his persona (his role as friend, son, high-school student, Eva pilot, etc.), and finally coming to terms with himself. Shinji, who has been struggling throughout the series to understand his place in the world, ends up realizing that "the whole is other than the sum of its parts"—citing Gestalt psychologist Kurt Koffka, who stressed that 'other' does not mean 'greater,' since it is not a matter of addition, but rather of the whole and the parts operating on indifferent planes-and that he is but himself, apart from the mental image of him others may hold.

The second sequence spans over five minutes of episode 26 , and starts with Shinji's face fading into a sketched version of it (00:09:33, 

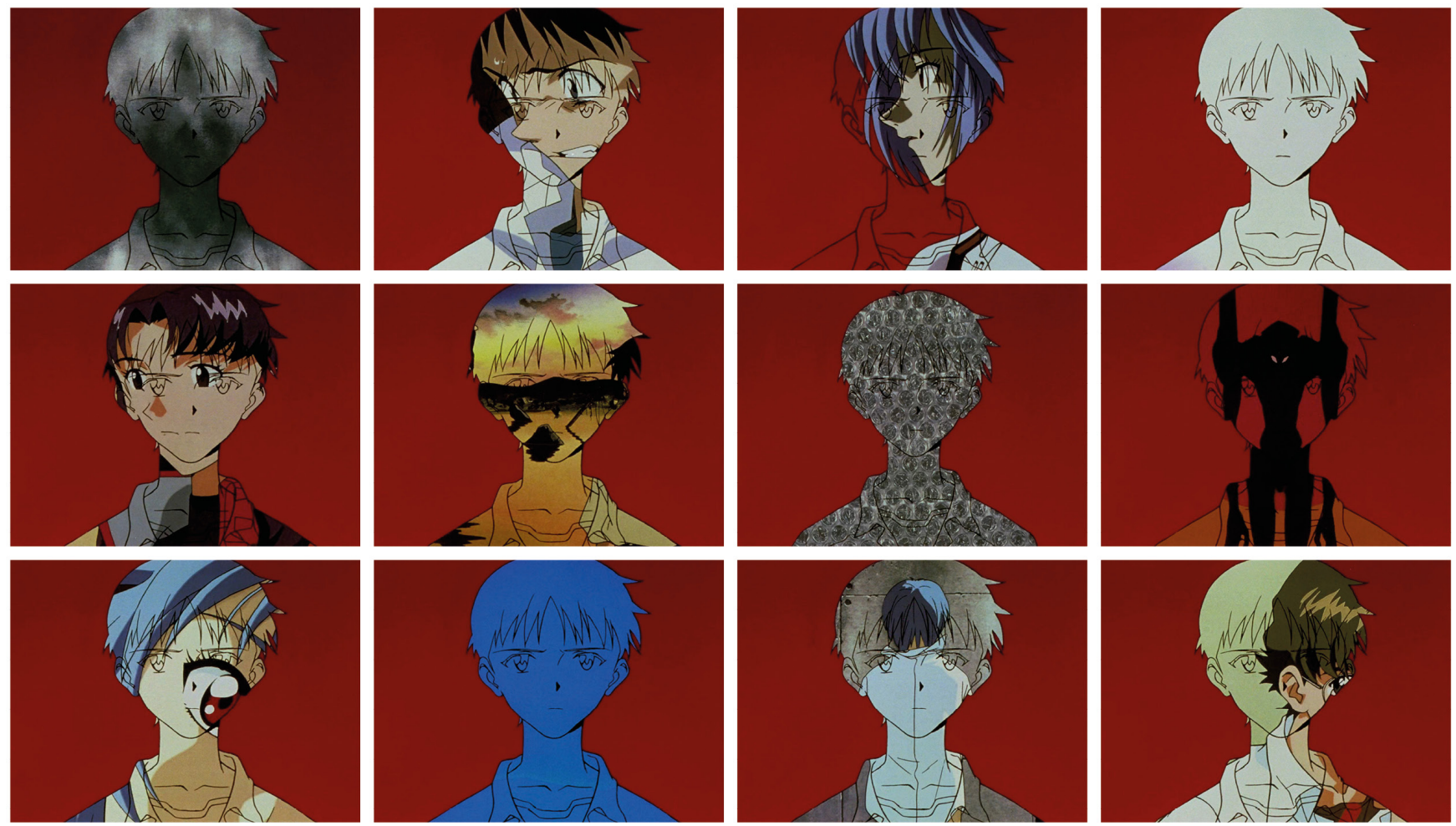

Figure 1.6. Twelve frames of Shinji's face intertwined with other materials (from scanned textures to images from previous episodes) in episode 26. (C) khara, inc.
Fig.I.7), almost as if Anno had resorted to the intermediate materials, color drafts and storyboard images. From this point onwards, the whole sequence is rendered with sketch-style images, quite stylized, as if drawn by pencil and poorly colored with rough strokes of markers. However, these hand-drawn images act as a representation of Shinji's introspective journey. The deeper he dives into his psyche, the simpler the drawings become, reducing his body to a minimum (a trembling silhouette on a blank sheet of paper). Ultimately, this hand-drawn quality emphasizes the line in an almost meta-referential way: At some point (oo:I I:57), Shinji's outlined body is floating on a white canvas (lit., "a world where you can do whatever you want"), but suddenly he is given a "restriction" (sic), as explained by the 

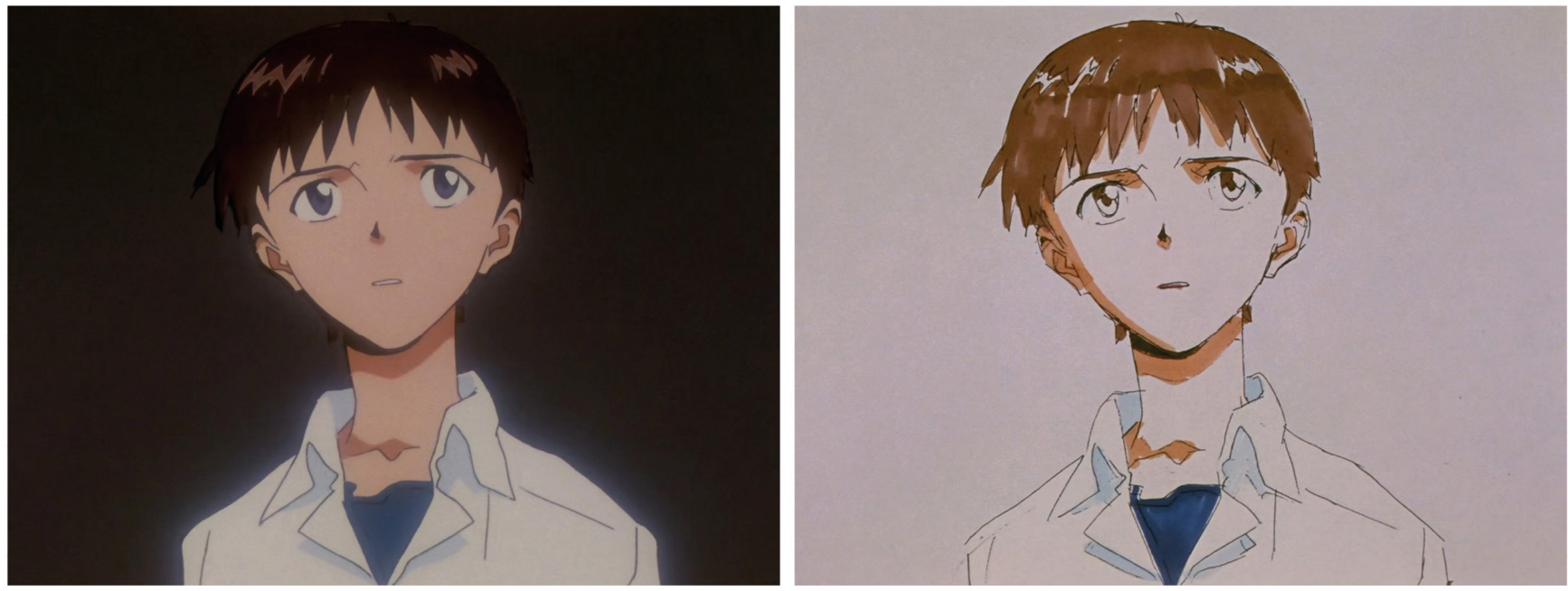

voice-over that is leading the sequence, and a line is drawn under him-emphasized by the squeaky sound of a marker-a line that becomes the horizon (Fig.I.8), creates a sense of gravity and roots Shinji to the newly created ground.

For several decades, and until the generalization of contemporary CG animation techniques, animating anime has involved multiple overlapping celluloid layers combined into a single image or frame. Characters and objects are outlined, and together with the limited tone-shading provide a sense of flatness and a drawn quality. EVA's episodes 25 and 26 push forward this drawn quality to an almost artistic and experimental facet, unexpected in mainstream anime. However, sometimes this hand-drawn finish is used for simple narrative purposes, to represent a flashback, or highlight an emotionally dramatic scene. Such is the case with EVA.

The third sequence adds an additional layer to the deconstruction process of the graphic image, abstracting the images-and therefore Shinji's psyche-to the very essence of animation. Paul Wells defined
Figure 1.7. Scene from episode 26, as Shinji morphs into a sketched version of himself. (c) khara, inc. 

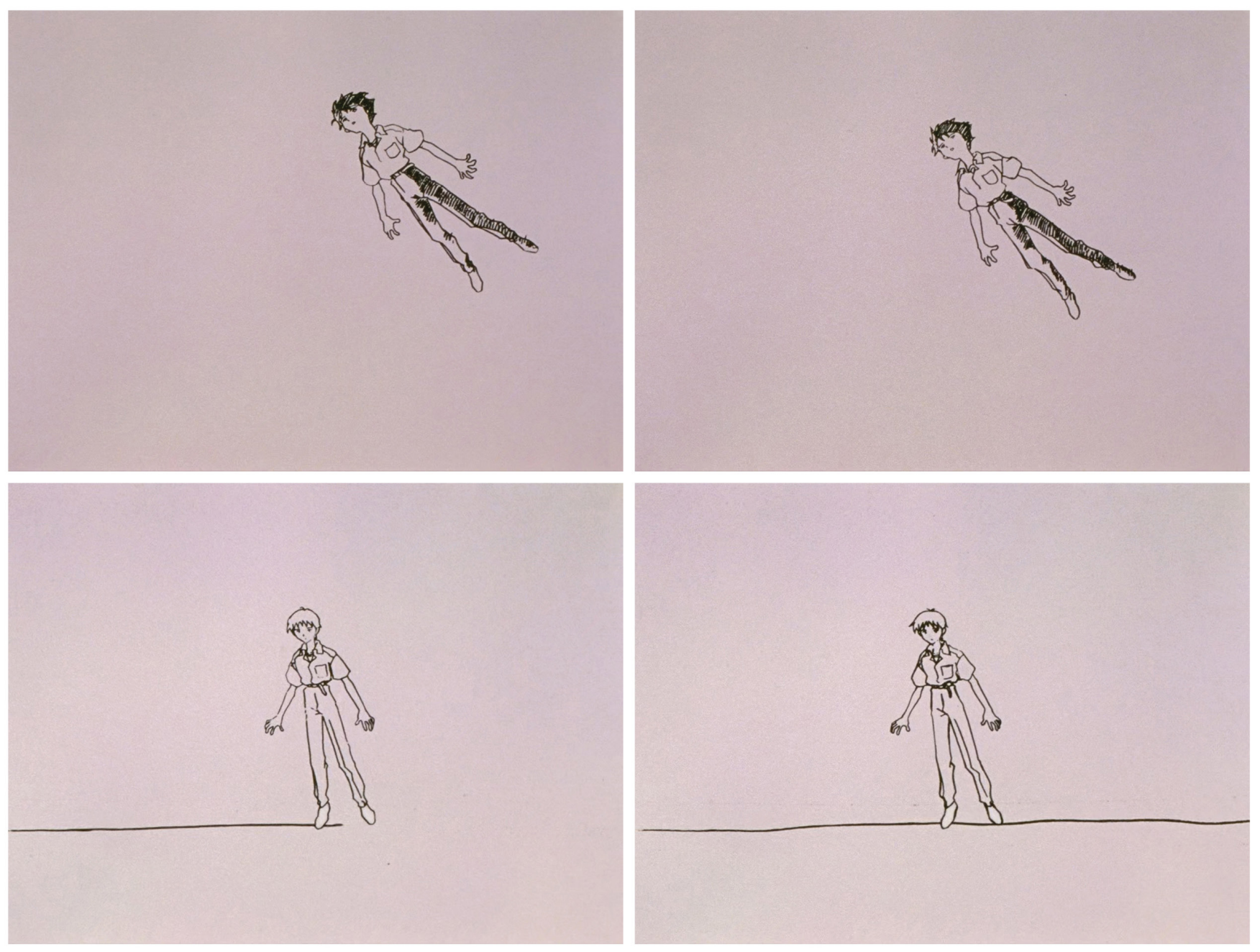

Figure 1.8. Shinji's sketched body is suddenly grounded by a drawn line (episode 26). (c) khara, inc. animation as "the artificial creation of the illusion of movement in inanimate lines and forms" (I998: I0). As Shinji himself voices out, "I feel like I am disappearing," the image becomes a simple oscillating black line on a blank canvas (oo:13:18) and a random doodle made up of lines with different thicknesses (Fig.I.9), without discernible meaning, which dance to the rhythm of the undergoing dialogue that dominates the scene. This naif pattern keeps morphing into different 

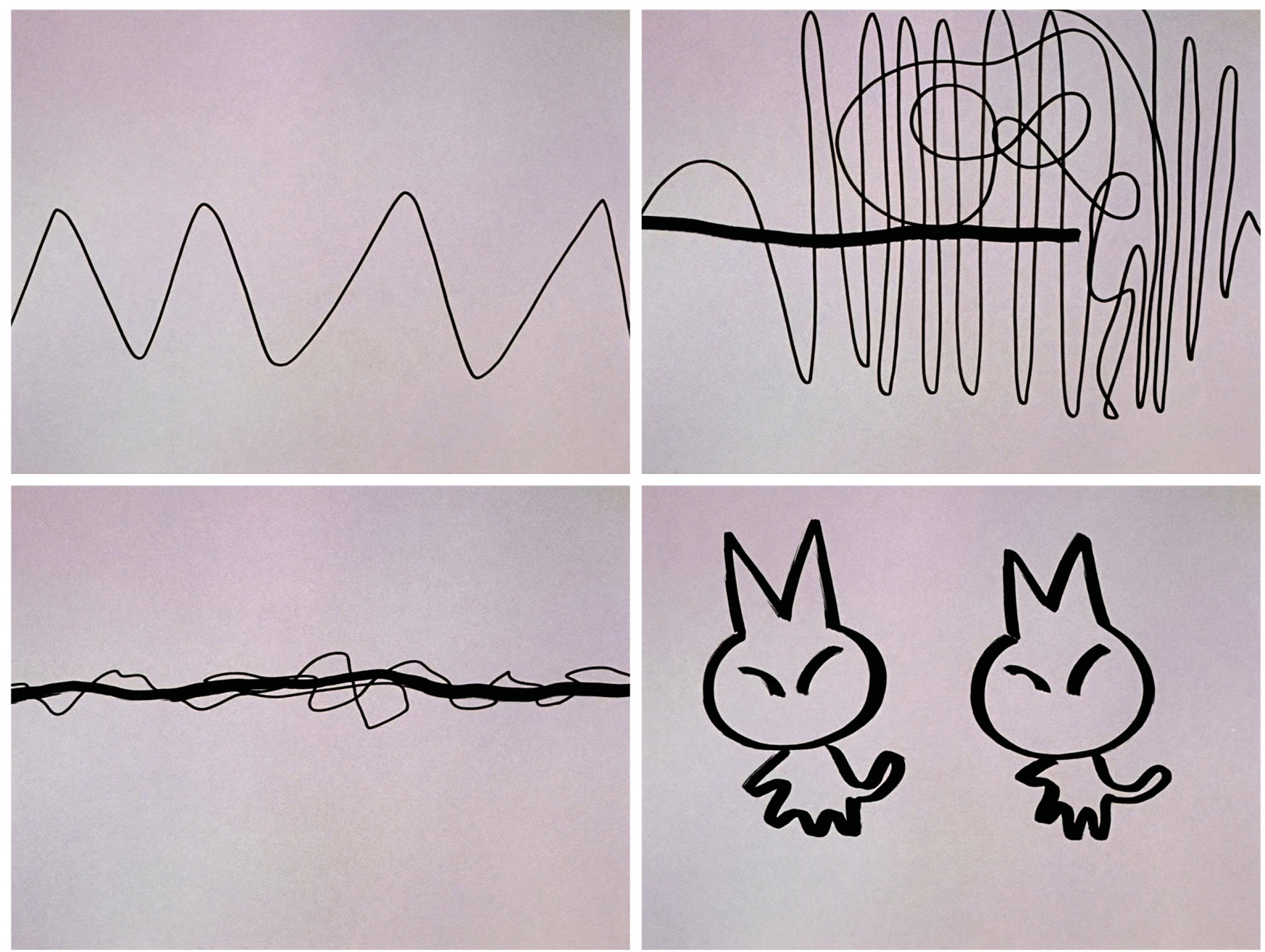

child-like drawings and finally becomes, once again, a sketch of Shinji himself as he begins to come to terms with his own dilemma.

Figure 1.9. Doodling drawings in episode 26. () khara, inc.

\section{Groundworks of EVA}

In a way, these three sequences work as a journey not only to the psyche of the protagonist, but also as an introduction to the groundworks 
of anime, emphasizing the role of stillness and the dynamic immobility of the image, the importance of line as opposed to volume, and the simple realization that anime is, essentially, drawings in movement.

Through EVA, anime is presented not as much as immobility, but as a significant amount of movement from different still elements. In a simple sense, this specific type of motion better refers to two or more still images (on two or more different planes) and how they move around, rather than drawing the different steps of a given movement (see Lamarre on "moving drawings" [2002: 359]). It is not all about stillness per se, but a different kind of movement that does not necessarily rely on smoothness and a naturalistic approach. In EVA, movement can be achieved through stillness, thanks to the parallax effect, background displacement of still images (pulling cels), and the potential that arises between frames, which Lamarre fully addressed when talking about the multi-planar space in The Anime Machine. In a similar fashion to speed-lines in comics, a single cel with an abstract patterned background moving in a direction opposite from the figure in the foreground can increase the sense of depth and motion, and achieve an emotional intensity.

However, at the beginning of this chapter, I argued that anime is not just immobility. If we look beyond stillness, anime is defined by what I called ratio dynamism, as a result of using a variable frame-per-second proportion which ultimately shapes the pace and rhythm of anime productions. Still images that can last one minute-building up tension and creating an atmosphere of strangeness-and large sections of different episodes which are almost entirely comprised of static frames are combined with sophisticated sequences, rendered in smooth animation. Moreover, I have presented EVA as a paramount example of the use of visual and sound synecdoches. Particular attention was paid to the role of close-ups as a significant type of visual synecdoche, and the large abundance of such devices in anime as a distinct trait from other filmic media-together with the prolonged still images 
consisting of a single frame, and the camera moving away from the human characters to highlight background unanimated objects as main descriptors of the ongoing action. ${ }^{11}$ Ultimately, anime appears as something entirely different from other animation (neither Disneystyle, high-end productions, nor low-cost, limited cartoons): a specific media form characterized by a series of narrative, aesthetic and filmic devices of its own.

\section{References}

Azuma, H. (2009). Otaku: Japan's Database Animals. Minneapolis, $\mathrm{MN}$ : University of Minnesota Press. (Introduction and translation by J. E. Abel and S. Kono)

Burch, N. (1979). To the Distant Observer: Form and Meaning in Japanese Cinema. Los Angeles, CA: University of California Press.

Chandler, D. (2002). Semiotics: The Basics. New York: Routledge.

Cohn, N. (2007). Japanese Visual Language the Structure of Manga. Visual Language Lab. Retrieved from: http://visuallanguagelab.com /P/japanese_vl.pdf (2013). The Visual Language of Comics: Introduction to the Structure and Cognition of Sequential Images. London: Bloomsbury.

Gan, S. H. (2008). The Newly Developed Form of Ganime and its Relation to Selective Animation for Adults in Japan. Animation Studies, 3, 6-I7.

Groensteen, T. (2007). The System of Comics. Jackson, MS: University Press of Mississippi.

Grosoli, M. and Massuet, J.-B. (eds.) (20I4). La capture de mouvement: Ou le modelage de l'invisible. Rennes: Presses Universitaires de Rennes.

Horno López, A. (20I4) El arte de la animación selectiva en las series de anime contemporáneas. Con A de Animación. Valencia: Universidad Politécnica de Valencia, vol. 4, 84-97.

Jakobson, R. \& Halle, M. (I956). Fundamentals of language. The Hague: Mouton.
II. Yet another way to create dynamism or, as Burch explains, "the tension between the suspension of human presence (of the diegesis) and its potential return" (I979: I6I). 
48

Anime Studies

Lamarre, T. (2002). From Animation to Anime: Drawing Movements and Moving Drawings. Japan Forum, I4, 329-367.

. (2009). The Anime Machine: A Media Theory of Animation. Minneapolis, MN: University of Minnesota Press.

McCloud, S. (I993). Understanding Comics: The Invisible Art. New York: HarperCollins.

McWilliams, D. (ed.) (I99I). Norman McLaren: On the Creative Process. Quebec: National Film Board of Canada.

Steinberg, M. (2012). Inventing Intervals: The Digital Image in Metropolis and Gankutsuō. Mechademia, 7, 3-22.

Steinberg, M. (2012). Anime's Media Mix: Franchising Toys and Characters in Japan. Minneapolis, MN: University of Minnesota Press.

Wells, P. (I998). Understanding Animation. Abingdon-on-Thames, UK: Routledge.

Whatsit, S. P. (20I3). Metonymy, Synecdoche, and the Disorders of Contiguity. Padova: libreriauniversitaria.it. 